\title{
Transforming Consumer Experience: When Timing Matters
}

\author{
Kathryn A. Braun-LaTour, University of lowa \\ Michael S. LaTour, University of Mississippi
}

How advertising can influence or change consumers' product experience has been a topic of great interest to marketers. The majority of research has suggested that advertising received prior to an experience can exert the most influence. In 1999, however, Braun introduced the concept of reconstructive memory, and demonstrated that advertising received after an experience can alter how consumers remember their experience. The issue of which order of framing of an experience through advertising is most influential on consumer memory has not yet been investigated. A constructive memory framework that can take into account both forward-and backward-framing effects and an experiment that tests hypotheses regarding the presentation order of advertising and experience is presented. The implications for the study of transformational advertising are discussed.

Advertising has been said to transform consumer experience, that is, rendering it different than it might have been with-out the advertising information (Hoch and Deighton 1989; Puto and Wells 1984). Researchers who have looked at advertising presented before and after the experience have concluded that advertising can have the greatest effect on this transformation process when presented first (Hoch and Ha 1986; Levin and Gaeth 1988; Marks and Kamins 1988), due to the law of primacy. It is therefore not surprising that the majority of the work that deals with the transformative nature of marketing communication has been framed to look forward, where the experience is seen as confirming or disconfirming expectations generated by advertising (e.g., Boulding et al. 1993; Olson and Dover 1979). In 1999, Braun published a paper demonstrating that advertising received after an experience could act as a "backward frame" and have a significant impact on how that experience was remembered and evaluated.

Braun's work on reconstructive memory put to question earlier research purporting advertising's primacy effect on transforming consumer experience. A reconstructive view to memory finds that information presented closest to retrieval would be most influential, that is, information presented following a consumer experience. However, Braun only looked at the presentation of 
advertising received after an experience. No research yet has considered the role of order of advertising presentation for consumer memory of an experience. Nor has research attempted to bridge together these disparate research findings on experiential framing to determine whether it is primacy or recency that drives how advertising transforms consumer experience (and memory for that experience).

The purpose of this research is to integrate the forward-and backward-frame effects into a more comprehensive model of experiential framing that takes into account both the constructive and reconstructive nature of memory. Although the order of information presentation has been one of the most investigated issues in social psychology, the conclusions that can be drawn from it for the experiential framing situation are weak (see Haugtvedt and Wegener 1994 for a review). Indeed, a theoretical explanation that can explain both primacy and recency effects has been missing (Rosnow and Robinson 1967). To understand how advertising transforms consumer experience, this research posits that not only order, but also time when judgments are made, should be taken into account. We begin by reviewing past research on forward framing, and discuss how it has neglected issues involving long-term memory. We then present a comprehensive view of memory that better explains how and when forward-and backward-framing effects may occur. An experiment that looks at the differential effects of order of advertising on consumer memory over short and longer time periods is presented. The implications for transformational advertising research are then discussed.

\section{Conceptual Background}

\section{Forward Framing Review}

Researchers who have investigated the effect of the order of message presentation on

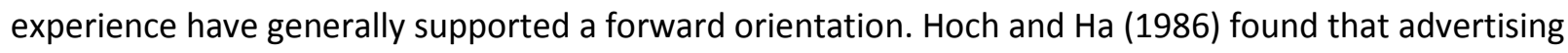
influenced judgment to a greater extent when presented first, through encoding processes, than when presented later through biased retrieval of the direct product experience. The notion that secondhand information is less effective when it is perceived after a direct experience is consistent with results reported by Levin and Gaeth (1988), who found the influence of a frame to be somewhat greater when

presented before the experience of eating ground beef than it was when presented afterward. Similarly, Marks and Kamins (1988) found that attitude change is significantly greater for those exposed to an advertising-experience sequence than for those exposed to the reverse sequence. Hoch and Deighton (1989), summarizing the effects of marketing communication on how consumers learn from their experiences, conclude that managers can exert the most influence before an experience ensues. 


\section{$\underline{\text { Timing of Judgments }}$}

Research supporting the forward framing in marketing, con-ducted in tightly controlled lab settings, had concluded that redefinition by advertising after an experience was quite rare (Alba and Hasher 1983). The rationale for the external applicability of these forward-framing experimental results has been that evaluation occurs spontaneously during a product experience (Fazio, Zanna, and Cooper 1978), and that information received in advance can direct attention within the product experience and influence what gets into the memory bin (Deighton 1984). This view follows a reproductive theory of memory that implies that stored mental representations of past experiences are elicited intact during recall (Reber 1985). According to this view, advertising information that is introduced after the experience is transmitted to the referent bin for permanent storage and should theoretically not affect which aspects of the experience can be subsequently recalled (Wyer and Srull 1980).

Consumer researchers (e.g., Hastie and Park 1986) have distinguished two types of judgments: on-line and memory-based. On-line judgments rely on what is currently in working memory, whereas memory-based judgments depend on retrieval of information from longer-term storage. These judgments involve different brain regions-the hippocampal area in on-line conscious perception of an event, the right prefrontal cortex in memory retrieval (Schacter 1996). Depending on one's view of memory, the information used during these tasks may also change.

According to the traditional reproductive view of memory, the outcomes of an on-line and memory-based decision should not differ if judgment is made immediately on presentation of the information (Feldman and Lynch 1988). Thus, the forward-frame dominance found in the marketing laboratory situations should transfer to the real world, where consumers would use a judgment referral strategy in which they would call up their previously formed evaluations from memory at some later time (Hastie and Park 1986). According to Lingle and Ostrom: "It is possible that the information a person selectively samples from memory and considers when making a memory-based judgment will be similar in composition to the information available when the initial stimulus-based judgment was made, especially when both judgments occur close in time" (1979, p. 180).

If one considers that memory is reconstructive and continuously changing, however, then one has to question whether the forward-frame effects would occur to the same degree in memory-based decision making. 


\section{Constructive and Reconstructive Memory}

Memory is a dynamic process, involving encoding, storage, and retrieval. Braun (1999) presented a model demonstrating how information interacts in memory (see Figure 1). Her interest was in how information presented after an experience altered how consumers remembered their experience, as portrayed on the right side of the diagram. In her research, she found that a bad orange juice experience could be remembered as being better in retrospect if advertising were received afterthe-fact. The advertising acted as a "backward frame," altering how consumers remembered and identified their sensory experience with the juice. She found that the language in the advertising "overshadowed" the consumer's direct perceptual experience of the juice, so that in recall, consumers incorporated the language of the advertising to express their own experience. Braun notes that the majority of advertising re-search has been on the left side of the diagram, where a "for-ward frame" theory has been used to account for how prior information acts as a memory schema and influences the perception of a current experience (Alba and Hasher 1983; Bower, Black, and Turner 1979).

Advertising can influence consumers both when it precedes and when it follows an experience. To consider its impact on the nature of experience, however, we need to look at the underlying processes of perception and memory. The perception of an experience involves information moving from a brief sensory store to short-term memory or the working memory system (Baddeley 1994) that organizes information as it stores it. Advertising can implicitly color the direct experience by affecting how individual neurons code information during the encounter (Merzenich and deCharms 1996). An ad viewed prior to a product or service encounter can frame how a consumer perceives it by influencing the contents of working memory over the course of the experience. Because consumers are biased to "see what they expect to see," images elicited by ads can increase the likelihood of a positive product or service experience (Cohen 1996). In that way, the advertising biases how the experience is encoded into memory (Hoch and Ha 1986). 
FIGURE 1

Dynamic Memory Process

\begin{tabular}{|c|c|c|c|c|}
\hline \multicolumn{3}{|c|}{ Acquisition processes } & \multicolumn{2}{|l|}{ Retrieval processes } \\
\hline $\begin{array}{l}\text { Acquisition of } \\
\text { original experience } \\
\Downarrow\end{array}$ & \multicolumn{2}{|c|}{$\begin{array}{l}\text { Acquisition of } \\
\text { subsequent information } \\
\Downarrow\end{array}$} & & \\
\hline $\begin{array}{l}\text { Decision } \Rightarrow \text { about } \\
\text { what to look at }\end{array}$ & $\begin{array}{l}\text { Integration } \Rightarrow \\
\text { of information into } \\
\text { some } \\
\text { representation }\end{array}$ & $\begin{array}{l}\text { Integration } \Rightarrow \\
\text { of new information } \\
\text { into the } \\
\text { representation }\end{array}$ & $\begin{array}{l}\text { Regeneration } \Rightarrow \\
\text { of the altered representation }\end{array}$ & Response \\
\hline
\end{tabular}

Source: Braun (1999).

In the wake of the experience, ads can no longer direct consumers' attentional resources; consumers have already learned from their consumption. When an advertisement is received postexperience, it can be used to help consumers re-construct their prior experience. Reconstruction is more likely when there has been a time lag between the experience and the ad presentation (Braun 1999). When advertising is presented immediately after an experience, and judgments are made, both pieces of information are available in memory and consumers will opt for the more diagnostic one, their own experience (Feldman and Lynch 1988). That is, evaluations by consumers who assess their experiences immediately after consumption will exhibit a primacy (or forward-frame) effect (as in Hoch and Ha 1986; Levin and Gaeth 1988; Marks and Kamins 1988). This prediction is consistent with the judgment literature, which finds that primacy effects tend to be greater when participants make on-line judgments, because the initial information is used as an anchor and insufficient adjustment occurs (Lopes 1982).

It is suggested that in a memory-based situation, when consumers have had a direct product experience, they will attempt to reconstruct it for use in decision making because of its perceived diagnosticity over other types of information, such as advertising (Feldman and Lynch 1988). Loftus (1982) suggests that this reconstruction process can be influenced by two types of information: schema and induced. We have schema reconstruction when people fill in gaps with expected information from their general knowledge (which may include information learned previously from advertising or other sources), and induced reconstruction when externally presented information such as postexperience advertising initiates the recollection process. An ad perceived prior to an experience can act as a schema and help to organize the retained information for storage in long-term memory (Wyer et al. 1982). Such frames of reference enable consumers to better under-stand and remember their brand experiences.

Although prior information can be helpful in encoding a subsequent experience, in the memorybased decision environment we would expect an ad frame that comes after to exert more influence by 
serving as a cue to reconstruct memories of the experience (Feldman and Lynch 1988). Others suggest that the encoding of an experience for which consumers have no reference frame might be subject to even more constructive retrieval processes because of the absence of restraints on its formation (Alba et al. 1981).

Although it is suspected that advertising can exert both forward- and backward-frame effects on evaluation, one of the purposes of presenting the constructive memory framework is to distinguish how advertising exerts an impact on the process. Strategic memory retrieval is a two-step process involving an initial guided memory search where the information is retrieved from long-term memory, and then followed by a monitoring process that evaluates the outcome of the search. To differentiate the memory processes evoked in remembering, some researchers have assessed the phenomenological aspects of recall. For instance, upon asking participants to remember their experience, in addition to the memory content, they are also asked how the memory felt to them.... did it seem like they were reliving the event, or did it seem more vague, familiar somehow to them, but they couldn't explain why. Endel Tulving (1985) distinguished these two states as "remembering" and "knowing," and psychologists and marketers have used this measure to gain insight into the quality or feeling associated with the remembering (e.g., Braun 1999; Dewhurst and Conway 1994; Gardiner 1988; Rajaram 1993). Tulving proposed that the probability of the "remember" response could serve as an index of the extent to which autonoetic (explicit) consciousness is involved in the recovery of past events, where "know" represents semantic or declarative knowledge. These two different states can be informative to advertising researchers as well; for instance, advertising that causes one to feel his or her experience again ("remembering" it) might be considered to have more of an impact than an advertisement that leads to more general knowing of an event.

This research investigation also assesses whether consumers are aware of the impact advertising has on their evaluations. This aspect of the research has practical implications for advertising studies that have employed self-reported measures of the influence of ad campaigns as well as public policy issues. Due to an illusion of control bias concerning their own experiences (Langer 1975), consumers' capacity to detect the intrusion of advertising might be diminished. Deighton speculated that "for mundane and inconsequential product choices, the consumer may adopt a hypothesis (from advertising) on such slight grounds that $s$ /he would be reluctant to acknowledge its role to others" (1984, p. 767). This unaware-ness of influence is consistent with research on memory-based decision making (Braun 1999). Consumers might believe their decision making to be driven by their own experiences, un-aware that external information can distort their memories (Loftus and Pickrell 1995). 
Schacter (1996) notes that the feeling associated with remembering, that is, of re-experiencing the past, can trick us into believing in the accuracy of our recollections regardless of their actual veridicality.

While past research has speculated that advertising received prior to an experience can alter the consumers' actual experience, no research yet in the forward-framing literature has found a change in the actual sensory perception of the experience. For instance, while consumers in the Olson and Dover (1979) study said the coffee was less bitter when they had received advertising, there was no way to gauge whether or not they actually tasted (experienced) a different coffee than those who did not receive the advertising. In Braun's (1999) study, however, consumers who received the postexperience advertising identified having tasted a different (better) juice than they had actually consumed.

\section{Experimental Overview}

The present study was designed to isolate the effects of an advertising message on consumers' evaluations of a taste experience, taking into account when judgments are made. The on-line decision environment follows past framing paradigms wherein the advertising frame is presented immediately be-fore or after the product experience, and an evaluation is made immediately after all information has been received. For the memory-based situation, the advertising information was presented before or after the experience and a distraction task (as per Braun 1999).

Following Braun (1999), our stimuli were orange juice and very favorable print advertising. We chose to investigate the worst orange juice Braun tested in her study (which was mixed with water, vinegar, and salt). Typically, the more ambiguous experiences have been the ones most subject to change (Hoch and Ha 1986). One of the most surprising aspects of Braun's 1999 study, however, was the finding that even a really bad orange juice-one that was watered down and tinged with vinegar and saltcould be made more favorable in retrospect. Might similar findings occur if no time had passed and judgments were made immediately? Or might contrast occur? The present research is designed to investigate what may become either a boundary effect in the framing literature, or to extend the framing research to a wider array of product experiences.

As in Braun (1999), our measures of interest included the recall (in the memory-based situation) or description (in the on-line environment) of participants' taste experience, and within those statements, we were interested in the length, the valence of the words, and whether participants had usurped words from the advertising to represent their own experience. We also included a recognition test where participants were asked to identify the sample they had recently tasted from among four other choices, and as they made their choice, to indicate their confidence, and whether the choice 
involved "remembering," "knowing," or "guessing." Consistent with the judgment (or framing literature), we also had participants form an overall evaluation of their experience and indicate how they came to their judgment (i.e., what sources of information were used). Because tasting the orange juice was such a bad experience, the transformative impact of the advertising could be assessed through its ability to make the recall more positive, identification of the perceptual experience more favorable, and the overall evaluation higher.

\section{Hypotheses}

Our first hypotheses are presented to compare the on-line versus memory views of framing and to predict an interaction effect:

Hypothesis 1a: Following the work of Levin and Gaeth (1988), Hoch and Ha (1986), and Marks and Kamins (1988), we posit that consumers asked to make a judgment about information presented serially in an on-line form will show a primacy effect, where by advertising presented before the product experience will influence the experience description, identification, and overall evaluation more than advertising presented afterward.

Hypothesis 1b: Replicating Braun (1999), and building on the reconstructive view of memory, we expect consumers asked to make an evaluation sometime after a product experience will be subject to a recency effect, where by the advertising received after the product experience will exert greater effect on recall, identification, and evaluation than if received before the experience.

The following hypothesis predicts a main effect of time:

Hypothesis 2: A time lag will increase the likelihood of reconstruction, resulting in the advertising exerting even greater effect on the evaluation of the experience, because the experience will decay in memory, and the advertising will be used to "fill in" the gaps as memory reconstruction occurs. This will be indicated in the recall/description measures, identification, and overall evaluation.

The following hypothesis relates to the ecphory of the experience and relates specifically to the memory-based conditions where remembering is involved:

Hypothesis 3: Tulving's R/K measure (which asks participants to identify whether their memory is associated with "remembering" or "knowing") will differentiate advertising's influence on encoding and retrieval processes. We expect more" remembering" when the ad is a cue for reconstruction, that is, when the experience has had time to fade and the advertisement is presented close to retrieval. 
An overall hypothesis regarding the awareness of influence in the framing process is presented:

Hypothesis 4: Consistent with past research, we expect consumers to have little awareness as to how much the advertising has influenced their memories and judgments. We expect consumers to indicate that they rely more on their experience when making decisions than on the advertising information.

\section{Experimental Investigation}

\section{Participants}

The participants were 180 undergraduates ( 82 female, 98 male) who received course credit for their involvement.

\section{$\underline{\text { Design }}$}

A two-order (ad comes before and after experience) $\mathrm{X}$ two-time (on-line and memory-based judgments) between-subjects design was used. Control was provided by running baseline measures for both the judgment and memory-based situations where participants received the taste experience but no advertising. Participants were randomly assigned to one of these six conditions.

\section{Method}

Efforts were made to make the experiment as similar as possible to Braun (1999). Participants came to the setting expecting an orange juice taste test. The same cover story was used, where the experimenter said she was running the study for an outside company and that participants should report only their true feelings about the juice, even if it was negative, because truthful feedback would most benefit the company. Depending on their experimental condition, participants either first received a two-ounce sample of the "bad" juice or received the same two ads used in the Braun 1999 study. One ad featured the historical origins of the company; the other was comparative, touting the freshness and quality of Orange Grove's oranges and superior distribution system. Those in the ad-first conditions were given five minutes to review and rate the advertising. Those in the experience-first conditions were told that this Orange Grove juice was new to the market and that they should evaluate the taste.

Participants in the on-line conditions were given the other piece of information-advertising or taste immediately following. Their evaluations of the orange juice were made right after that last piece of information had been received. Participants in the memory conditions who received the advertising first received the same five-minute background distraction as had been used in Braun (1999) between 
the advertising and experience. Those participants then tasted the Orange Grove juice and had a longer, 15-minute distraction, before they filled out the questionnaire. Participants in the after-experience memory condition followed the same timing as Braun (1999): After they tasted the juice, they received a 15-minute distraction, followed by the advertising evaluation, then an-other five-minute background information distraction where they filled out some background information regarding on-line activity and media usage, and then, finally, the questionnaire. Participants in the control conditions tasted the juice, and in the on-line condition, they immediately evaluated it; in the memory condition, they were presented with the 15- minute distraction as well as the five-minute background survey distraction before evaluating the juice.

Consistent with Braun 1999, the questionnaire began with having participants recall (or describe for the on-line conditions) in their own words their taste experience with Orange Grove juice. They were asked to pick three words that best described their memory of Orange Grove's taste. Then came the identification task. Participants were given five samples of orange juice and were asked to identify the one they re-membered having tasted earlier in the hour. They were told that one among the five samples was exactly as they had tasted earlier. The samples were numbered 1 to 5 , with 1 being the worst tasting and 5 being the best (these samples followed the same recipe as used in Braun 1999, with sample 2 representing the juice they had tasted). They were told to sample each in numeric order and to defer making identification until all five had been sampled. They were offered crackers to cleanse their palate between each sample.

After sampling, participants were asked to distinguish between states of awareness using the process developed by Tulving (1985), where they were to indicate a "remember" judgment if their identification approached a reexperiencing of the product, that is, if they could taste the juice "in their mind's eye"; a "know" judgment if their identification was based more on familiarity; and a "guess" if their identification strategy involved randomly guessing one of the samples to be a match. They also rated their confidence that their identification was correct, on a scale anchored by 0 (not at all sure correct) to 100 (extremely sure correct).

Participants then formed overall evaluations on the juice on the same eight scales used by Braun (1999). These were 10-point scales, where more favorable evaluations received higher scores. Three additional scales were added to investigate consumers' decision strategies: "How well did the advertising information represent your own taste experience with the OJ?"; "How well do you believe the advertising fairly represented the juice?"; and "Did you rely more on the advertising or your taste experience when making your judgments?" If the participant relied more on the advertising, he or she 
would circle a number closest to the left side of the scale, and if the participant relied more on his or her taste experience, he or she would circle a number toward the right end. These were 10-point scales, with higher numbers indicating more agreement and fairness to the advertising (for the first two scales), and more reliance on the taste experience on judgment (third scale). Participants were also given an open-ended question that asked them to explain how they formed their judgments of Orange Grove juice.

\section{$\underline{\text { Results }}$}

\section{Coding Procedure}

Two independent judges coded participants' recall statements of their taste experiences. They had no knowledge of the experimental hypotheses. Their interrater reliability was .95, and an average was used for the analysis.

Recall

Participants had five minutes to describe in detail their memory (or experience, for the on-line conditions) of their taste experience of Orange Grove juice. The judges coded the number of words, the number of independent thoughts, the number of positive and negative thoughts, the number of ad words used in the recall statement, and the number of positive, negative, and ad words chosen to describe the juice. The results by condition appear in Table 1.

We did a preliminary analysis and found that all the ad conditions were significantly more positive than the control conditions (this was true also for recognition and evaluation measures). Because our primary interest was in investigating how the order and timing of the ads influenced consumers' recall and judgments about the taste of the orange juice, the analysis includes only the ad conditions. As per Hypothesis 1a, we expected lesser effects when the ad came after the experience when judgments were made immediately, and per Hypothesis $1 \mathrm{~b}$, greater effects when the ad followed the experience in the memory situation. Overall, we expected the ads to exert greater influence over time, in the memory conditions, as per Hypothesis 2. We used ANOVA (analysis of variance) to test these hypotheses, with time and order and their interaction as the factors and the recall items as the dependent variables. It was expected that time would be a significant factor (where longer time would yield greater influence) and the interaction would also be significant (and follow-up tests would reveal specific pat-terns of influence). We'll begin with a discussion of the measures of length: words and thoughts. (Note: No specific hypothesis was forwarded regarding the length of the recall statements; the 
purpose here was to get a gauge of how much was written.) The overall model was significant for the amount written, $F(3,119)=5.64, p=.0012$, and time was significant at $F(1,119)=10.64, p<.0015$, with Bonferonni post hoc tests finding significantly more words for the on-line conditions, $M=29$, than the memory conditions, $M=22$. The interaction was also significant, $F(1,119)=5.25, p=.02$, where the after condition had a significantly longer recall in the on-line than in the memory condition; these conditions were also found to be significantly different at $p<.05$ in post hoc tests. The model for the number of thoughts was not significant.

Our hypotheses dealt with the content of the recall statements. Here the overall model for percentage of positive thoughts was significant, $F(3,119)=10.17, p<.0001$, and both time and the interaction were significant: $F(1,119)=12.71, p=.0005$ for time, and $F(1,119)=17.42, p<.0001$ for the interaction. The main effect of time showed more positive thoughts for the memory conditions, $54 \%$, than the on-line period, $29 \%$, significantly different at $p<.05$. As predicted, for the on-line condition, there were more positive thoughts when the ad preceded the experience than when it followed; the opposite was true in the memory conditions, where the postexperience advertising exerted the most influence. Post hoc tests found these conditions to be significantly different. The percentage of negative thoughts told a similar story: The overall model was significant at $F(3,119)=7.39, p=.0001$, and both time, $F(1,119)=13.96, p=.0003$, and the interaction, $F(1,119)=8.21, p=.005$, were significant factors. Post hoc tests revealed less negative thoughts (29\%) in the memory conditions than in the on-line conditions (49\%). The interaction revealed the same pattern as with the positive thoughts, where in the on-line condition there were less negative thoughts when the ads preceded the experience, and in the memory condition there were less negative thoughts when the ads followed the experience. These findings are consistent with what we predicted in Hypothesis $1 \mathrm{a}$ and Hypothesis $1 \mathrm{~b}$, where the beforeexperience presentation exerts greatest influence when it comes first when judgments are made online, and when judgments are made over time (memory-based), the after-experience ad exerts the most influence. Also, consistent with Hypothesis 2, the ads exert more influence on judgment as time passes, regardless of the order of presentation.

Braun (1999) suggests that the transformational words used in the advertising (i.e., words such as "fresh," "sweet," "pulpy," and "pure," which directly referenced the taste of the juice and were designed to conjure up that experience in the reader's mind) "overshadowed" the experience, causing the participants to remember a different-tasting juice. In the typical overshadowing study, the verbal information is presented after the perceptual experience. As a type of source confusion error, Braun found that those who received the advertising were more likely to use the ad words to describe their 
own taste experience. In the present study, we found similar results. However, the verbal information from the advertising also influenced the schema of the taste perception when it preceded the experience. We found the overall model for the ad words to be significant, $F(3,119)=5.83, p=.001$, but only the interaction was significant, $F(1,119)=21.67, p=.0002$. Participants used significantly more ad words when the ad preceded the experience in the on-line condition (as compared to the after condition), and significantly more ad words when it followed (rather than preceded) the experience in the memory-based conditions. It appears that the usurping of words is part of advertising's framing effect overall.

The participants had the opportunity to pick three words (free recall, no list provided) they felt best represented Orange Grove's taste. These were coded for positive, negative, and ad-based content. For the positive word content, the over-all model was significant at $F(3,119)=8.9, p<.0001$; time was significant at $F(1,119)=15.35, p=.0002$; and the interaction was significant at $F(1,119)=9.08, p=$ .003. As with the recall statements, there were significantly more positive words used in the memory conditions, $M=1.80$, than in the on-line conditions, $M=1.0$. And as with the differential or-der hypothesis (Hypothesis 1a and Hypothesis 1b), there were more positive words used when the ad preceded the experience in the on-line conditions and when the ad followed the experience in the memory-based conditions. Not surprisingly, based on the previous findings, the negative words followed a similar pattern. The overall model was significant at $F(3,119)=5.48, p=.0015$; time was significant at $F(1,119)=6.81, p=.01$; and the interaction was significant at $F(1,119)=9.61, p=.002$. There were significantly more negative words used in the on-line conditions than the memory conditions, $M=1.2$ versus $M=.7$. There were significantly more negative words used when the ads followed the experience in the on-line condition and when the ads preceded the experience in the memory condition. The model for the ad words was not significant. As the reader will note in Table 1, all conditions used the ad words to describe the juice's taste.

As stated earlier, we found all advertising conditions to be significantly more positive in recall than the control conditions. In other words, a frame effect occurred despite the high contrast between the bad juice and the favorable advertising. Even with the condition that showed the greatest degree of contrast, when the ad followed the experience in the on-line condition, there was influence by the advertising. These results replicate Braun (1999) and extend the forward-framing results to unambiguous experiences (Hoch and Ha 1986). For instance, Levin and Gaeth predict that at some point there should be a contrast effect: "If the ground beef tastes terrible, for example, it is unlikely that even a powerful positive frame will lead to a favorable evaluation" (1988, p. 378). 


\section{Memory Identification}

Participants were asked to pick the sample that they had tasted earlier. The distributions for each condition appear in Table 2.

Our interest was in whether or not the advertising information would positively transform the perceptual memories of consumers' taste experiences indicated by participants' willingness to choose a more favorable sample to represent their original experience if they received the ads. A categorical data analysis procedure was used to analyze the means of the conditions, with time, order, and the interaction as factors. We found all factors to be significant: time, $\chi^{2}(N=120)=6.71, p=.0096$; order, $\chi^{2}(N=120)=9.46, p=.002 ;$ and the interaction, $\chi^{2}(N=120)=22.04, p<.0001$. The on-line condition showed less influence, $M=2.45$, than the memory-based condition, $M=2.96$. The order effect was driven by the inter-action due to the lack of effect, almost contrast, in the on-line after-experience condition, with $M=2.43$ for after and $M=3.0$ for before. As found in the recall statements, the type of order effect depended on time: The before-experience in the on-line condition had a higher identification score, $M=3.23$, than the after-experience condition, $M=1.63$, and the after-experience condition had higher identifications in the memory situation, $M=3.13$, than the before-experience, $M=$ 2.80. Notice the greater difference, however, in the on-line condition: The ad appears to make identification much more negative when it follows the experience, resulting in almost a contrast effect in judgment, which could explain why past framing researchers had concluded that advertising received after an experience was not an effective strategy.

Tulving's R/K (and added " $G$ ") was used to differentiate how the advertising had influenced the memory of the juice: Higher numbers of "remember" judgments would demonstrate more influence at retrieval, whereas more "know" judgments would indicate more influence at the encoding, thus testing Hypothesis 3. We did not expect any differences in the reporting of these judgments in the on-line conditions, as the experience was available in working memory; hence, there was no need to reconstruct the taste experience. We expected that if the advertising was exerting more influence on retrieval in the after conditions, there would be more reporting of "re-member" in the memory condition than if the ad preceded the experience, where it would more likely influence the en-coding of the experience. Because advertising is likely to influence the experience in both these ways, it is important to find a measure that can differentiate these effects. We found more "remembering" in the memory-after condition, $60 \%$, than in the memory-before condition, $33 \%$, significantly different at $\chi^{2}(\mathrm{~N}$ $=60)=4.28, p=.03$. There were no such differences observed in the on-line condition. 
Unlike the $\mathrm{R} / \mathrm{K} / \mathrm{G}$ measure, the confidence measure did not differentiate at all between conditions; all conditions reported confidence to be around 66 to 68 on the 100-point scale. The ad conditions showed similar confidence by those who did not receive the advertising (control) conditions. These results are also consistent with Braun (1999), who found that even the most misled consumers were highly confident in their decisions.

To provide some insight into why the ads may be exerting greater influence over time, we compared the control conditions where judgments/memories were taken in the on-line and memorybased time frames. Hypothesis 2 predicts that over time, the experience will fade, allowing the advertising to exert more influence. We found greater accuracy in identification within the on-line time frame, $56 \%$, versus $33 \%$ in the memory-based time frame, significantly different at $\chi^{2}(N=60)=3.29, p=$ .06 .

\section{Overall Evaluations}

An interesting question is whether the advertising made the participants enjoy their experience more, or dislike the experience less. Figure 2 charts the means of the overall evaluation index (and provides a more detailed description of the measures involved in that index). The eight subjective measures loaded on one factor, with coefficient a of .95. They were combined to form an index of subjective evaluation. The over-all model was found to be significant at $F(3,119)=7.11, p=.002$, with time significant at $F(1,119)=9.65, p=.002$ and the interaction significant at $F(1,119)=11.56, p=$ .0009. Again, the advertising exerted more influence over time, with $M=4.26$ for the on-line condition, and $M=5.6$ for the memory-based condition. Evaluations were significantly higher when the advertising preceded the experience in the on-line condition, and when the advertising followed the experience in the memory-based condition. If one considers the midpoint of the scale as an "average" rating, it appears that "liking" for the juice only developed in the memory conditions; participants in the on-line conditions just disliked the juice less.

Usage of Information

The usurping of the advertising words in the participants' re-call statements is an indirect measure of source monitoring errors: They believed those words represented their own experience when in fact they unknowingly "borrowed" them from the advertising. At the end of the experiment, we were interested in how the participants perceived how they made their evaluations and judgments. Would they readily acknowledge the influence the advertising had on their judgments? Or would they 
believe it was their own taste experience that drove their evaluations, as predicted in Hypothesis 4 ? We first looked at what the participants wrote in the open-ended question that asked them to describe how they came to evaluate Orange Grove juice. A large majority said "taste," and a large subset of those mentioned that they compared the taste of Orange Grove to other juices they had tasted. There was no mention of the advertising having influenced those taste judgments.

TABLE 2

Taste Recognition

\begin{tabular}{cccccrrr}
\hline & & On-line & & \multicolumn{2}{c}{ Memory } \\
\hline Sample identified & Before & After & Control & Before & After & Control \\
\hline 1 & 2 & 13 & 12 & 5 & 2 & 14 & 10 \\
2 & 7 & 13 & 17 & 10 & 5 & 3 \\
3 & 8 & 3 & 1 & 6 & 6 & 3 \\
4 & 8 & 1 & 0 & 4 & 6 & 0
\end{tabular}

Note: The boldface for sample 2 represents the sample of orange juice that participants actually tasted, and indicates that accuracy was better during the on-line control condition than in the memory control condition where time had passed. Sample 1 was even more watered down with vinegar and salt than sample 2, and the samples got progressively better as the numbering increased (meaning less water, salt, and vinegar). Sample 5 was actually Minute Maid orange juice made according to directions.

FIGURE 2

Overall Evaluations

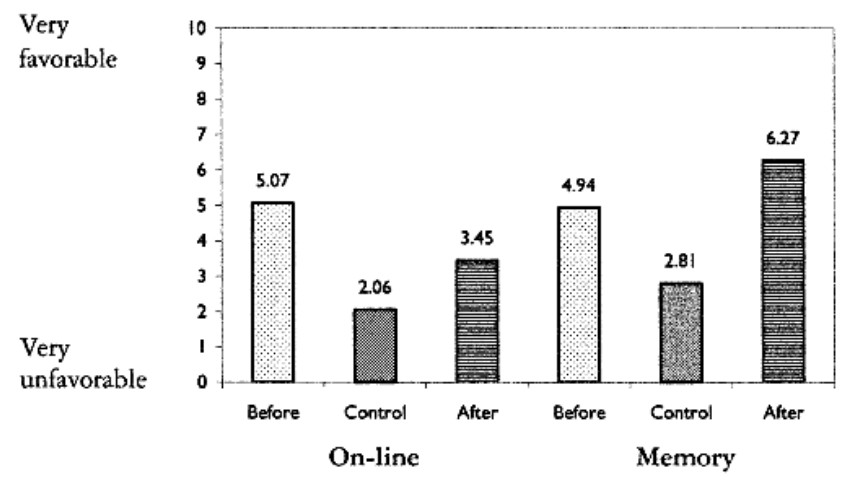

Notes: The overall evaluation index was formed by taking the average of the following items (they loaded on one factor with Cronbach's $\alpha=.95$ ): Overall, how would you rate the quality of the new Orange Grove orange juice? $(1=$ poor, $10=$ excellent); How much would you like to have a whole glass of the Orange Grove orange juice ? $(1=$ very little, $10=$ very much); Compared to your favorite orange juice, how would you rate Orange Grove's quality? $(1=$ poor, $10=$ excellent $)$; How likely is it that you would buy Orange Grove if it were available in your area? $(1=$ not very likely, $10=$ very likely); Would you recommend the Orange Grove brand of orange juice to your family or friends? $(1=$ definitely no, $10=$ definitely yes); What are your overall feelings toward the Orange Grove orange juice? $(1=$ very unfavorable, $10=$ very favorable. The following two affect scales were converted to values from 1 to 10 and included in the index:

Here are some faces expressing various feelings.

Which face comes closest to expressing how you feel about the Orange Grove orange juice?

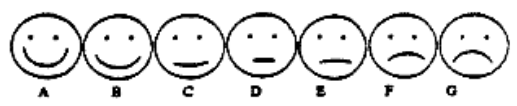

Where would you put your feelings toward Orange Grove on the feeling thermometer?
WARM $100^{\circ}$ - Very warm or favorable feeling $85^{\circ}$ - Good warm or favorable feeling $70^{\circ}$ - Fairly warm or favorable feeling $60^{\circ}$ - A bit more warm or favorable than cold feeling $50^{\circ}$ - No feeling at all $40^{\circ}-\mathrm{A}$ bit more cold or unfavorable feeling $30^{\circ}$ - Fairly cold or unfavorable feeling $15^{\circ}-$ Quite cold or unfavorable feeling
COLD $\quad 0^{\circ}$ - Very cold or unfavorable feeling

On the scales, participants rated how they perceived the advertising, that is, whether they thought it "matched" their own experience and how fair they thought it was. These measures were found to be highly correlated, $r=.81$, so they were combined. This combined scale was found to be negatively correlated with the third scale, $r=-.21$, which reported how much reliance was placed on the 
experience versus advertising, thus indicating that the more participants felt they relied on their own experience, the less they believed the advertising was fair and matched their own experience. This combined fairness measure was found to be positively correlated with the distortion of memory identification, so that people who felt the advertising was fair and matched their experience were more likely to pick a favorable juice to match their memory, $r=.34$. The self-report reliance on experience was not found to be correlated with memory identification, $r=-.01$.

We also looked at whether these usage measures varied across conditions. Consistent with Braun (1999), we found that most participants thought they were relying on their own experience the most when making judgments, $M=8.5$, for all conditions. However, the fairness measure did differentiate between those who were more influenced by the advertising: The overall model was significant at $F(3,119)=4.22, p=.007$; time was significant at $F(1,119)=5.66, p=.019$, and the interaction was significant at $F(1,119)=7.00, p=.009$. The ad was perceived as more fair and like their own experience in the memory conditions, $M=5.8$, than in the on-line conditions, $M=4.7$. The ad was seen as fairer in those conditions that were most influenced by the advertising: The before-experience in the on-line condition, $M=5.3$, versus the after-experience in the on-line condition, $M=4.2$, and the after-experience in the memory condition, $M=6.4$, versus the before-experience in the memory condition, $M=5.2$.

\section{General Discussion}

Academic research on the framing of consumers' experiences has had significant consequences for the design of advertising strategy (Hoch and Deighton 1989), where managers had been urged to present their advertising prior to the consumer experience. Braun's (1999) study suggested another strategy; using postexperience advertising to alter consumers' memories of their experiences.

The purpose of this research investigation was to both replicate and extend Braun's 1999 paper by studying the effects of time and order of advertising presentation on consumers' memories and evaluations of their direct taste experience. We replicated Braun's 1999 research finding that postexperience advertising could alter memory for that experience (our Hypothesis 1b), and extended it by demonstrating that prior received advertising could also contaminate the memory for the experience (though not to the same degree). We also found results consistent with judgment researchers' studies (e.g., Hoch and Ha 1986; Levin and Gaeth 1988) that find advertising can exert more influence prior to an experience when judgments are made on-line (Hypothesis 1a). 
In addition to finding this interaction effect, we found an overall main effect of advertising on transforming the experience. Braun (1999) found that a very bad experience could be altered in retrospect through very good advertising. Judgment researchers, however, who have mainly studied framing in on-line situations have concluded: "Even 'great' advertising is not going to make soyburgers taste better, double-knit leisure suits fit snugger, or Yugo cars ride smoother. These products provide clear-cut evidence not open to multiple interpretations" (Hoch and Ha 1986, p. 359). Now we are not so sure-even a very unambiguous taste experience was found to be influenced by the advertising. Note that the unambiguous bad taste of the juice can be verified in Table 1, where there were $0 \%$ positive words used by participants in the control condition.

The way advertising's primacy and recency affect experience transformation has to do with the timing. These differences in outcomes can be explained by the types of memory systems that exert the most influence on judgment. Memory-based conditions rely on long-term explicit retrieval, which is influenced by recently received information. Advertising presented in advance biases attentional resources during the experience, affecting the on-line condition, which taps working memory. This same prior information is used to organize the experience for storage, but it exerts less influence than if received just before recall. That different types of memory systems were at play in this experiment was evidenced by participants' reporting on the phenomenological qualities of their recollection, that is, whether they "remembered" the taste (meaning they could taste it in their mind's eye) or just "knew" it to be the correct one. The higher percentage of "remember" judgments for memory-based conditions when the ad is close to retrieval suggests greater use of advertising as a retrieval cue (Hypothesis 3 ).

Previous forward-framing studies looked only at how advertising affected overall judgments of a product. By distinguishing in this study between participants' own memories of past experiences (recognition) and their overall judgments, we were able to determine how internalized the advertising information had become that it did indeed "transform" the consumer experience. As in Braun's 1999 study, we found that when advertising acts in this manner, consumers rate their reliance on their own experience as high and advertising in-formation as low when making judgments (Hypothesis 4). Consumers are therefore not consciously aware of the intrusion that advertising has either on the construction or reconstruction of their experiences.

We shall now discuss our results in terms of how advertising managers can shape consumer experience, and consider some limitations and areas for future research. 


\section{Implications for Transforming Experiences}

Whether one views memory as a stable "memory bin" or as a constructive or reconstructive process has implications for advertising managers. For instance, Hoch and Deighton (1989, p. 8), suggest that memory reconstruction occurs only after long time periods and "may be more likely when outcomes are separated in time from original actions" (Snyder and Uranowitz 1978). Because consumers in natural settings generally do not encounter information in rapid sequential order as in the typical framing experiment, it is reasonable to question what Hoch and Deighton (1989) meant by "outcomes ... separated in time from original actions." Thus far, no one has tested the boundaries of the effects of time on consumers' learning from experience. We found time to interact with order in this investigation; past framing findings of supporting forward-framing dominance held only in the on-line situation.

This interaction enabled us to assess when the forward framing might be most likely to occur, such as on in-store advertising seen close to sampling. These forward-framing effects are likely to have their intended impact when they are consistent with assumptions and help shape the emergent expectations about a product or service outcome (e.g., Stayman, Alden, and Smith 1992). The forwardframe effects, though important, are only part of the framing story.

Alba, Hutchinson, and Lynch contend: "We have taken the relatively extreme position that the effects of long-term memory are so pervasive and fundamental as to cast doubt on the existence of any purely stimulus-based decisions in the real world. The basis for our position lies not only in the fact that few consumer decisions take place in the presence of complete information, but also in the belief that memory exerts itself even in stimulus-intense environments through its effects on attention and perception" (1991, p. 36).

Backward-frame effects may be more prevalent and are consistent with other findings in consumer research. Lodish's market-level data finds that advertising is most likely to be noticed after a consumer has bought the advertised product (Lodish et al. 1995). Studies of dissonance reduction (Cohen and Goldberg 1970) suggest that people may use postdecision information to reinforce the merits of a decision, thereby creating after-the-fact a greater sense of confidence in their initial decision than they may have actually experienced. The backward-framing effects are most likely to happen in situations for which consumers have had an experience, and as they decide whether or not to repurchase, they attempt to reconstruct that experience in their mind. Even communications intended to frame forward may also frame backward. For instance, advertising intended to influence cur-rent 
beliefs to encourage repeat purchase, brand switching, or even new product trial, may inadvertently alter interpretations of relevant prior consumption experiences.

Aaker and Stayman (1992) note the difficulty in studying the transformational effects of advertising and the lack of re-search on capturing the core concept, the actual difference in the perceptual experience accounted for by the secondhand information. Managers interested in studying how their campaigns influence consumers' perception and memories can use the present paradigm and its measures as a guide. For in-stance, one might show consumers different versions of the target ads before/after they experience the product. Thereafter, the company would take an assessment of that experience by asking them to recall/describe that experience in their own words. The company could determine the effectiveness of the different ads to transform by their ability to infiltrate those recall statements. In addition, by asking consumers to rate their memory using Tulving's R/K distinction, one can deter-mine how well the advertising interacted in the creation of an emotional recollection of that experience.

\section{Future Research and Limitations}

The present research is limited, as is any laboratory research, by the conditions under which data were collected. Braun (1999) found that over time, even more reconstruction occurred, so we would expect, had we had a week between the experience and the memory, that there would have been even more constructive effects due to the advertising. In addition, this research was conducted on a sample with an average age of 22; had we extended our subject base to include much younger and older consumers, we might have seen even more of an effect due to the advertising suggestion (Schacter 1996). Also, we chose to use the same design and stimuli as Braun (1999) in order to do as close a replication as possible. To be able to generalize the findings to other products, one might consider looking at products for which there are higher search or credence attributes than the more experience-based product studied in this research. Furthermore, since the advertising message quality might lead to different levels of effect, future research might consider varying the credibility or the format of the advertising.

In this research study, we attempted to limit the role prior knowledge would play (as a schema) by using a fictitious brand of orange juice (which was also done to be consistent with past framing research). We note that when our participants were asked about their decision strategy, the majority mentioned that they compared Orange Grove to other brands they had tested. So although we were able to rule out a prior brand schema of Orange Grove as having an effect on evaluation, the 
participants did use prior knowledge to come to their evaluations. Future research might consider testing a new-to-the world product where prior knowledge would be low. Or, research might consider the role of prior knowledge, such as whether or not more "expert" consumers would be less influenced by the advertising. Also, future research might consider advertising variables that best engineer the consumer experience in the short and long term: Might there be different techniques involved for online and memory experience framing?

\section{References}

Aaker, David A., and Douglas M. Stayman (1992), "Implementing the Concept of Transformational Advertising," Psychology and Marketing, 9(May/June), 2 37-253.

Alba, Joseph W., Susan G. Alexander, Lynn Hasher, and Karen Caniglia (1981), "The Role of Context in the Encoding of Information," Journal of Experimental Psychology: Human Learning and Memory, 7(July), 283-292.

— and Lynn Hasher (1983), "Is Memory Schematic?" Psychological Bulletin, 93 (March), 203-231.

_ J. Wesley Hutchinson, and John G. Lynch (1991), "Memory and Decision Making," in Handbook of Consumer Behavior, T. S. Robertson and H. K. Kassarjian, eds., New York: Prentice-Hall, 1-49. Baddeley, Alan (1994), "Working Memory: The Interface Be-tween Memory and Cognition," in Memory Systems, D. L. Schacter and E. Tulving, eds., Cambridge: MIT Press, 351-368.

Boulding, William, Ajay Kalra, Richard Staelin, and Valarie Zeithaml (1993), "A Dynamic Process Model of Service Quality: From Expectations to Behavioral Intentions," Journal of Marketing Research, 30 (February), 7-27.

Bower, Gordon H., John B. Black, and Terrence J. Turner (1979), "Scripts in Text Comprehension and Memory," Cognitive Psychology, 11 (April), 177-220.

Braun, Kathryn A. (1999), "Post-experience Advertising Effects on Consumer Memory," Journal of Consumer Research, 2 (March), 319-334.

Cohen, David (1996), The Secret Language of the Mind, San Fran-cisco: Chronicle Books.

Cohen, Joel B., and Marvin E. Goldberg (1970), "The Dissonance Model in Post-Decision Product Evaluation," Journal of Marketing Research, 7(August), 315-321.

Deighton, John (1984), "The Interaction of Advertising and Evidence, "Journal of Consumer Research, 11 (December), 763- 770. 
Dewhurst, Stephen A., and Martin A. Conway (1994), "Pictures, Images and Recollective Experience," Journal of Experimental Psychology: Learning, Memory and Cognition, 20 (September), 10881098.

Fazio, Russell H., Mark P. Zanna, and Joel Cooper (1978), "Direct Experience and Attitude Behavior Consistency: An Information Processing Perspective," Personality and Social Psychology Bulletin, 4 (Winter), 48-51.

Feldman, Jack M., and John G. Lynch, Jr. (1988), "Self-Generated Validity and Other Effects of Measurement on Belief, Attitude, Intention and Behavior," Journal of Applied Psychology, 73 (August), 421-435.

Gardiner, John M. (1988), "Functional Aspects of the Recollective Experience," Memory and Cognition, 16 (July), 309-313.

Hastie, Reid, and Bernadette Park (1986), "The Relationship Between Memory and Judgment Depends on Whether the Judgment Task Is Memory-Based or On-Line," Psychological Review, 93 (July), 258-268.

Haugtvedt, Curtis P., and Duane T. Wegener (1994), "Message Order Effects in Persuasion: An Attitude Strength Perspective," Journal of Consumer Research, 21 (June), 205-218.

Hoch, Stephen J., and John Deighton (1989), "Managing What Consumers Learn from Experience," Journal of Marketing, 53 (April), 1-20.

_ and Young-Won Ha (1986), "Consumer Learning: Advertising and the Ambiguity of Product Experience," Journal of Consumer Research, 13 (October), 221-233.

Langer, Ellen S. (1975), "The Illusion of Control," Journal of Personality and Social Psychology, 32 (August), 311-328.

Levin, Irwin P., and Gary J. Gaeth (1988), "How Consumers Are Affected by the Framing of Attribute Information Before and After Consuming the Product," Journal of Consumer Research, 15 (December), 374-378.

Lingle, John H., and Thomas M. Ostrom (1979), "Retrieval Selectivity in Memory-Based Impression Judgments," Journal of Personality and Social Psychology, 37 (February), 180-194.

Lodish, Leonard M., Magid Abrahamson, Stuart Kalmenson, Jeanne Livelsberger, B. Lubetkin, B. Richardson, and M. E. Stevens (1995), "How T.V. Advertising Works: A Meta- Analysis of 389 Real World Split Cable T.V. Advertising Experiments," Journal of Marketing Research, 32 (May), 124- 139. 
Loftus, Elizabeth F. (1982), "Memory and Its Distortions," G. Stanley Hall Lecture Series, Washington, DC: American Psychological Association.

_ (December), 720-725.

Lopes, Lola (1982), "Toward a Procedural Theory of Judgment," Wisconsin Human Information Processing Program, technical report, 17, 1-49.

Marks, Lawrence J., and Michael A. Kamins (1988), "The Use of Product Sampling and Advertising: Effects of Sequence of Exposure and Degree of Advertising Claim Exaggeration on Consumers' Belief Strength, Belief Confidence, and Attitudes," Journal of Marketing Research, 25 (August), 266- 281.

Merzenich, Michael M., and Richard C. deCharms (1996), "Neural Representations, Experience, and Change," in The Mind-Brain Continuum, Rodolfo Llinas and Patricia S. Churchland, eds., Cambridge: MIT Press, 61-82.

Olson, Jerry C., and Phillip A. Dover (1979), "Disconfirmation of Consumer Expectations Through Product Trial," Journal of Applied Psychology, 64 (April), 179-189.

Puto, Christopher P., and William D. Wells (1984), "Informational and Transformational Advertising: The Differential Effects of Time," in Advances in Consumer Research, vol. 11, Thomas C. Kinnear, ed., Provo, UT: Association for Consumer Research, 638-643.

Rajaram, Suparna (1993), "Remembering and Knowing: Two Means of Access to the Personal Past," Memory and Cognition, 21 (January), 89-102.

Reber, Arthur S. (1985), Dictionary of Psychology, London: Penguin.

Rosnow, Ralph, and Edward Robinson (1967), Experiments in Persuasion, New York: Academic Press.

Schacter, Daniel (1996), Searching for Memory, New York: BasicBooks.

Stayman, Douglas M., Dana L. Alden, and Karen H. Smith (1992), "Some Effects of Schematic Processing on Consumer Expectations and Disconfirmation Judgments," Journal of Consumer Research, 19 (September), 2 40-255.

Synder, Mark, and Seymour W. Uranowitz (1978), "Reconstructing the Past: Some Cognitive Consequences of Person Perception," Journal of Personality and Social Psychology, 36 (9), 941950

Tulving, Endel (1985), "Memory and Consciousness," Canadian Psychologist, 26 (January), 1 -12. 
Wyer, Robert S., and Thomas K. Srull (1980), "The Processing of Social Stimulus Information: A Conceptual Integration," in Person Memory: The Cognitive Basis of Social Perception, R. Hastie, T. M. Ostrom, R. S. Wyer, D. L. Hamilton, and D. E. Carlsons, eds., Hillsdale, NJ: Erlbaum.

_ Thomas K. Srull, Sallie E. Gordon, and Jon Hartwick (1982), "Effects of Processing Objectives on the Recall of Prose Material," Journal of Personality and Social Psychology, 43 (4), 674-688. 